momentum through endorsement by the ASEAN framework, which has facilitated resource mobilization from Japan. This region is at the heart of the flyway but has previously lacked conservation capacity.

These meetings signal a long-term process of institution building within the East Asian-Australasian Flyway, which is not only facing multiple threats but is embedded within a region of complex geopolitics and socio-economic diversity. Conservation of these migratory species is being championed by policy entrepreneurs who are crafting a way forward through various institutional arrangements. Multilateral efforts are thus well underway to avert waterbird extinctions; the question is whether they can gain traction before is too late.

For more information, see caff.is/arctic-migratory-birdsinitiative-ambi, and eaaflyway.net/.

EDUARDo Gallo-CAJIaO School of Biological Sciences and School of Earth and Environmental Sciences, University of Queensland, St Lucia, Queensland, Australia, and Center for Environmental Politics, University of Washington, Seattle, Washington, USA. E-mail e.gallocajiao@uq.edu.au

MICHA V. JACKSON School of Biological Sciences, University of Queensland, St Lucia, Queensland, Australia

Tong Mu (๑ orcid.org/0000-0002-2686-0725) Department of Ecology and Evolutionary Biology, Princeton University, Princeton, New Jersey, USA

RICHARD A. Fuller School of Biological Sciences, University of Queensland, St Lucia, Queensland, Australia

\section{Opportunities to boost protection of the grey parrot in Nigeria}

The grey parrot Psittacus erithacus is native to lowland moist forests of West and Central Africa, ranging from southeastern Côte d'Ivoire to Kenya and northern Angola. Once widespread, population declines have occurred in many areas, and in some instances have been severe (Ibis, 2016, 158, 82-91). In 2016 the species was categorized as Endangered on the IUCN Red List and in the same year concerns over the impact of capture of live grey parrots for international trade prompted their listing on Appendix I of CITES. In contrast to neighbouring range states, the capture and sale of grey parrots has been prohibited in Nigeria because the species is on schedule I of Nigeria's Endangered Species Decree of 1985 and its Endangered Species Act. Despite formal protection, a report to CITES in 2001 highlighted an ongoing threat to wild populations posed by the capture of young parrots and loss of habitat (P. McGowan, 2001, Status, Management and Conservation of the African Grey Parrot, Psittacus erithacus in Nigeria).
In response to concerns over the status of grey parrots in Nigeria (Ostrich, 2014, 85, 205-233) we recently initiated a rapid assessment of the scale and scope of trapping and trade. During 2018 we made visits to 28 sites in the states of Anambra, Delta, Bayelsa, Rivers, Cross River, Edo, Lagos, Oyo, Kwara, Kaduna and Kano. Interviews with local community members revealed that trapping, primarily the capture of chicks from nests, occurs at sites adjacent to at least five communities across the Niger Delta states. Trapping was found to be conducted by Ghanaians and Nigerians operating in the remote communities within Delta, Bayelsa, Rivers and Cross River states. Transboundary movements of grey parrots and parrot trappers between Nigeria and neighbouring countries, notably Cameroon, were also identified. Overt surveys of markets found live parrots and parrot body parts for sale openly in all of the 11 cities visited. All market vendors interviewed stated that they obtain parrots from more than one trapper and several, based in Kano, reported purchasing live and dead parrots, and parrot parts, from merchants coming from Cameroon. Notably, levels of awareness of regulations prohibiting trapping and trading of wild sourced grey parrots was low among market vendors ( $77 \%$ of vendors were unaware) and absent in all communities adjacent to capture sites in the Niger Delta except in Cross River state.

Red parrot tail feathers were found for sale in markets throughout Nigeria. They are used as charms and are incorporated by some local cultures into traditional attire. Harvesting of red feathers from beneath roosts provides a modest income for communities close to roost sites, but the collapse of wild populations threatens to undermine this practice. Our visit to a well-known parrot roost in the Ikodi community, River State, where thousands of parrots were previously recorded to roost (P. McGowan, 2001, op. cit.) found the roost to have been absent for at least 10 years. Its loss has been attributed to threats ranging from trapping of the parrots by non-Ikodians (Naturewatch, 2000, 34-35) to infrastructural developments.

The information collected during these rapid assessments highlights multiple opportunities to address the threats posed by capture and trade of grey parrots in Nigeria. Local communities can act as the first line of defense against illegal wildlife trade, and the situation revealed by our surveys suggests that locally appropriate communityfocused initiatives could be effective for addressing the capture of parrots in Nigeria. The design of such initiatives should consider opportunities to leverage the cultural and economic value of wild parrot populations to promote protection and encourage sustainable practices. There are also opportunities to increase awareness of the illegality of capture and sale of grey parrots among target groups, including communities living adjacent to wild populations, trappers, market vendors and civil society. A multifaceted strategy should also include efforts to improve enforcement 
at key points in the trade, including places where parrots are currently sold openly in large urban centres and at international borders, including the airports through which parrots enter international markets (Global Ecology and Conservation, 2018, 16, e00429).

IFEANYI M. EZENWA and CHRISTOPHER NWANI Department of Zoology and Environmental Biology, University of Nigeria Nsukka, Nsukka, Enugu State, Nigeria

E-mail ifeanyi.ezenwa@unn.edu.ng

UlF OtTosson A. P. Leventis Ornithological Research Institute, University of Jos Biological Conservatory, Jos, Nigeria

RowAN O. MARTIN World Parrot Trust Africa Conservation Programme, Hayle, UK, and FitzPatrick Institute of African Ornithology, University of Cape Town, South Africa

\section{Tricks of the trade-legal trade used to conceal Endangered African grey parrots on commercial flights}

Wild parrots are exported in large numbers from Africa, both legally and illegally, and the region accounts for a large proportion of global trade in all wild birds listed on the CITES Appendices. In the last decade three of the top four most traded birds were African parrot species, and reported exports of wild parrots from Africa during this time totalled 311,439 (Ostrich, 2018, 89, 139-143). In 2016 concerns over the impact of trade on wild populations led to the transfer of the grey parrot Psittacus erithacus, categorized as Endangered on the IUCN Red List, to CITES Appendix I.

Recent investigations into the trade in grey parrots have provided opportunities to observe how criminal actors exploit legal trade in parrots to traffic threatened and protected wildlife. In September 2018 an employee of a wildlife exporter based in the Democratic Republic of Congo (DRC) explained to investigators working for World Animal Protection how grey parrots are concealed within legal shipments of so-called green parrots. In the same month, monitoring by the World Parrot Trust of trade in parrots via social media revealed a shipment of grey parrots mixed with red-fronted parrots Poicephalus gulielmi. The shipment that originated in DRC was intercepted by customs on arrival in Kuwait and was accompanied by paperwork for other species. The parrots travelled on a flight operated by Turkish Airlines via Istanbul, a route identified as commonly used in the transport of wild parrots from Africa (Global Ecology and Conservation, 2018, 16, eoo429). In 2018 DRC established an annual export quota of 2,500 red-fronted parrots, which are locally referred to as 'green parrots'. Exports of red-fronted parrots from DRC have risen five-fold since grey parrots were transferred to Appendix I of CITES (mean exports during 2017-2018 compared with mean exports during 2012-2016; CITES trade statistics derived from the CITES Trade Database on 19 December 2018) and this increase may in part reflect an increase in the fraudulent use of permits to traffic grey parrots.

Furthermore, there is evidence that the legal parrot trade is being used as cover for the illicit trade in other wildlife, including threatened primates. An investigation led by the BBC into the trafficking of chimpanzees Pan troglodytes from West Africa led to the seizure of a legal shipment of parrots entering Nepal in which two young chimpanzees were found concealed in a hidden compartment (Nepal busts chimp smugglers after investigation, 10 October 2018, bbc.co.uk/news/world-asia-45808743). This shipment also travelled on a flight operated by Turkish Airlines via Istanbul. Monitoring of trade via social media (Global Ecology and Conservation, 2018, 16, e00429) has revealed further instances in which individuals trading in wild parrots also traded in other species. A Pakistan-based wildlife trader, for example, who on multiple occasions advertised grey parrots imported from Africa, as recently as December 2018 advertised specimens of several species of primates endemic to West and Central Africa. In September 2018 investigators working for World Animal Protection observed a bonobo Pan paniscus at a parrot holding facility in DRC.

Customs authorities and other enforcement agencies need to be vigilant to the risks posed by criminal actors misusing the legal trade and ensure that shipments of parrots originating in Africa are adequately inspected and are accompanied by the correct documentation. Carriers of shipments of parrots, primarily airlines, have a critical role to play by ensuring staff are adequately trained and that systems are in place for rapidly disseminating information on illegal activity to enforcement agencies. Immediate action in these areas would help airlines meet recent commitments made as signatories to the United for Wildlife Transport Taskforce Buckingham Palace Declaration to shut down the air transport routes exploited by wildlife traffickers.

Rowan O. Martin ${ }^{*}$ and CRISTIANa SENNI World Parrot Trust, Hayle, UK. E-mail rmartin@parrots.org

NeIL D'CRUZE† and NICK BRUSCHI World Animal Protection, London, UK

${ }^{*}$ Also at: Fitzpatrick Institute of African Ornithology, University of Cape Town, South Africa

†Also at: Wildlife Conservation Research Unit, Department of Zoology, University of Oxford, Oxford, UK 